\title{
THE PRENATAL DEVELOPMENT OF THE HUMAN FEMUR ${ }^{1}$
}

\author{
WILLIAM J. L. FELTS \\ Department of Anatomy, Cniversity of Michigan, Ann Arbor ${ }^{2}$
}

TEN FIGURES

Despite the large volume of literature devoted to the skeletogenous and to quantitative studies of the developing and mature skeleton, the manner of growth and development in toto of a prenatal long bone never has been comprehensively investigated. Only in the early stages of development, up to the onset of diaphysial ossification, has the topic been well explored. For the femur in particular, knowledge of the early period is based chiefly on the work of Bardeen and Lewis ('01), Bardeen ('05), Braus ('04), Friedländer ('01), and Altmann ('24). In addition to discussing early femoral development, Pitzen ('23) made a quantitative comparison of several pre- and postnatal stages, presenting his data in reduced tabular form with no consideration of growth rates. From approximately the time of diaphysial ossification on, with the exception just noted, the literature is concerned mainly with certain isolated characteristics, torsion for example.

It was felt that unless the developmental trends of the bone as a whole are known, the investigation of a single facet of its organization would have only limited utility. In this study the prenatal development of the human femur has been investigated quantitatively, and growth and growth rates along several dimensions have been determined and expressed

\footnotetext{
${ }^{1}$ Based upon a dissertation submitted in partial fulfillment of the requirements for the degree of Doctor of Philosophy in the University of Michigan.

${ }^{2}$ Present address: Department of Anatomy, Tulane University, New Orleans, La. 
graphically. An attempt has been made to relate the observed growth and shape changes to certain basic processes already described in the literature.

\section{MATERIALS AND METHODS}

This study is based on 53 femurs, one each from a series of fetuses and one from an infant; the material, available in the Embryology Collection and from the morgue of the Department of Anatomy of the University of Michigan, is of unknown racial stock. The crown-rump lengths ranged from 31 to $485 \mathrm{~mm}$ and the spine lengths from 26 to $410 \mathrm{~mm}$. The minimum and maximum ages estimated from these measurements were 9 th week to term and one infant of three weeks postnatal. The age-size data of Mall ('18) and Streeter ('21), as modified and used in the Michigan Department of Anatomy (Patten, '46), were used in these estimations.

The femurs were carefully removed with no selection as to side. Muscle and connective tissues were removed as completely as possible, but the periosteum was left intact. The specimens were cleared in glycerin after being stained with Alizarin Red $\mathrm{S}$ in $\mathrm{KOH}$ in order to demonstrate the extent of ossification. In general, the process follows that utilized by Noback and Noback ('44), with variations in the strength of $\mathrm{KOH}$ depending on the size of the specimens. Measurements taken before and after processing indicated that distortion of cartilage or bone was insignificant. The possibility of distortion during storage may be pertinent because the majority of fetuses above $150 \mathrm{~mm}$ were morgue specimens preserved by freezing, and almost all the remaining ones had been preserved for varying lengths of time in formalin. However, this should not be considered a critical factor for, as has been pointed out by Krahl and Mueller ('47), no significant shrinkage or swelling of either cartilage or bone is produced during or following formalin fixation.

In order to measure the smaller femurs with essentially the same degree of accuracy as the larger ones, and especially to prevent distortion or damage to the more delicate speci- 
mens, I devised the following procedure by which all measurements were taken from enlarged line drawings:

1. Using a vertical copying camera, a photograph was made of the frontal aspect of the femur as it rested on condyles and trochanter.

2. On an enlarged line drawing made from this negative, 11 points were placed, one at the center and 5 on either side of center, along the middle half of the shaft. This arbitrary, but constant, longitudinal axis served as a line of orientation for the various measurements taken from the frontal drawing as well as a means of positioning the femur for photographs of other aspects.

3. The femur was then so placed on a glass slide of appropriate length that the previously determined longitudinal axis could be aligned with an orientation line scribed on the glass. This could be done with great accuracy under a dissecting microscope and checked with measurements on the frontal drawing.

4. The glass slide with the femur was next placed on a small turntable mounted in front of a mirror which was fixed at $45^{\circ}$ so as to direct the reflected image upward toward the vertical camera.

5. By rotating the turntable and focusing the camera on the reflection, it was possible to take photographs parallel with (medial aspect) and at right angles to (superior and inferior aspects) the original longitudinal axis.

All the line drawings were made to an approximately constant enlargement of $22 \mathrm{~cm}$ for the overall length of the femur. This size was chosen because, without being too large, it approaches that of the femur of a three-year-old child and admits accuracy comparable to that attained in studies of postnatal material. Measurements were taken with a millimeter rule $(0.5 \mathrm{~mm}$ scale), dividers and protractor to the nearest half millimeter or half degree. In converting the linear measurements taken from the line drawings, the value was divided by the magnification (dependent upon the original specimen size) and expressed in millimeters and tenths of 
millimeters. Repeated measurements of a sample series of drawings indicated an accuracy within a tenth of a millimeter.

The descriptions of certain other technical procedures used in the investigation are given in later sections where pertinent.

\section{OBSERVATIONS AND DISCUSSION}

\section{Dimensions}

Each dimension used in an investigation of this type should fulfill two requirements. First, it should represent, in its changes, a part or all of the growth of one, or in special summation cases more than one, of the various regions of the femur throughout the period covered by the study. Second, the dimension should be such that the technique utilized in its determination is equally applicable to both the oldest and the youngest specimen in the series being studied. In view of this, the dimensions measured in the present series have been kept to a minimum. From the following definitions of dimensions (figs. 1, 2) it will be seen that some are adaptations of the standard osteometric techniques used previously (e.g., Martin, '28; Hrdlička, '20; Ingalls, '24), while others were devised to meet particular needs of this study.

1. Total length of shaft from infracondylar plane to highest point of greater trochanter, measured along the determined longitudinal axis of the femur.

2. Overall length of femur from infracondylar plane to highest point on femoral head, measured on a line perpendicular to the infracondylar plane. The value of this dimension is affected by torsion, by inclination, and by obliquity of the shaft.

3. Length of ossified shaft from highest to lowest point on ossified shaft, measured along the determined longitudinal axis of the femur.

4. Length of proximal cartilage from proximal chondroosseous junction to highest point on greater trochanter, measured along the determined longitudinal axis of the femur. 
5. Length of distal cartilage from distal chondro-osseous junction to infracondylar plane, measured along the determined longitudinal axis of the femur.

6. Bicondylar width across condyles, measured at greatest width perpendicular to the determined longitudinal axis.

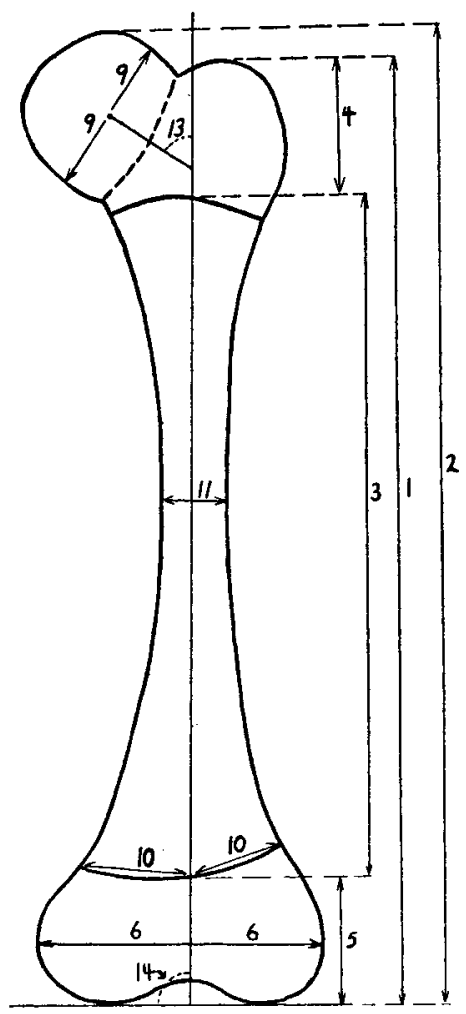

Fig. 1 Dimensions of the prenatal human femur, determined on frontal drawings. Numbers refer to definitions on pages $4-7$ in text.

7. Anterior-posterior diameter of condyles from the retrocondylar plane to a point midway between the anteriormost surfaces of the two condyles.

8. Head-trochanter width - greatest distance across head and greater trochanter, measured on the line drawing of the superior view. Measured in this manner, the dimension is affected only by the inclination of the head and neck, not by 
torsion; measured on the frontal drawing, it would be affected by both.

9. Diameter of head - average of two measurements of greatest head diameter, one perpendicular to the line established for inclination, and one perpendicular to the line for torsion.

10. Diameter of chondro-osscous junction in the younger specimens in which the ends of the ossified shaft are fairly straight, this dimension is measurable as the distance across the junction of cartilage and bone. In the older specimens the junction is curved and the measurement is taken from each side to the intersection of the junction with the deter-
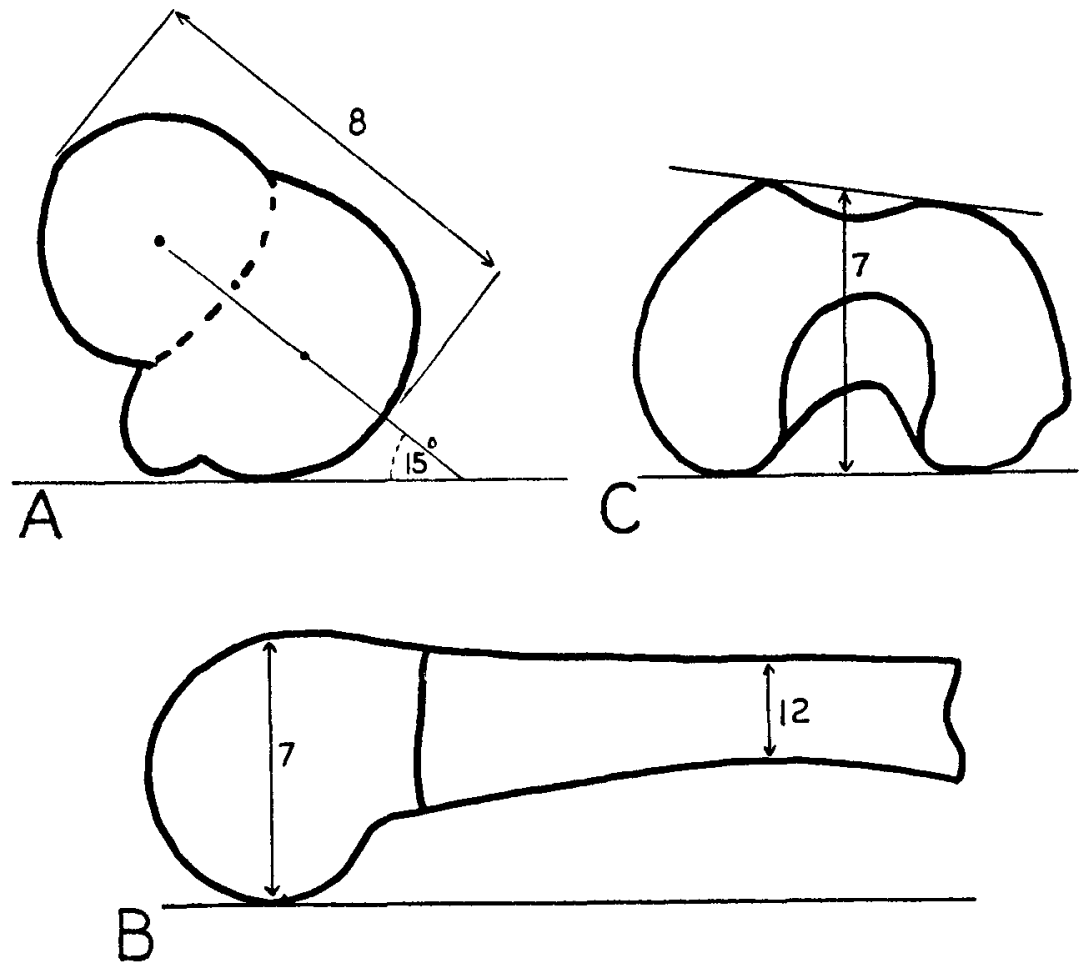

Fig. 2 Dimensions of the prenatal human femur, determined on drawings of the superior (A), medial (B) and inferior (C) aspects. Numbers refer to definitions on pages $4-7$ in text. 
mined longitudinal axis of the femur. Because the diameter of the proximal junction appears less in proportion to the degree of torsion present, this dimension is rendered invalid in most specimens. Only the distal junction measurement, therefore, is used in this study.

11. Minimum medial-lateral diameter of shaft across ossified part of shaft at narrowest point, medial to lateral.

12. Minimum anterior-posterior diameter of shaft across ossified part of shaft at narrowest point, anterior to posterior.

13. Inclination of head and neck angle with the determined longitudinal axis of femur made by a line drawn to it from determined center of head and passing through a point midway across the junction of head with neck. Although it would be preferable to carry this line through center points in the neck, the extreme shortness of the neck and the fact that torsion in many older specimens causes it (on frontal drawings) to appear non-existent make such a procedure impractical. As determined thus, inclination is affected by the degree of torsion.

14. Obliquity of shaft - laterally opening angle made by infracondylar plane with the determined longitudinal axis of the femur.

15. Torsion angle with the retrofemoral plane made by a line extending from the determined center of head through to a point in center of greater trochanter. The retrofemoral plane, that plane on which the femur rests on condyles and trochanter, is here assumed to be identical with a frontal plane through the femur.

\section{Growth areas}

In analyzing the growth of a long bone it is necessary to relate the progressive morphological changes, as much as possible, to the basic features of its organogenesis. The configuration of specific regions must be visualized in terms of the behavior of their constituent tissues during the develop- 
mental period. The growth of the whole bone is, then, the resultant of these several growth processes and their interaction. This approach has been used in reference to the postnatal development of the femur and of long bones in general, but it had not been extended to prenatal stages.

The generally accepted concepts of appositional and interstitial growth in cartilage, of appositional growth alone in bone, of row formation and associated phenomena in cartilage adjacent to advancing ossification, and of resorption, all hold for the prenatal period as for the postnatal period. The differences between the pre- and postnatal periods are, as will be discussed at length in a later section, mainly differences in the relative proportions and spatial relations of the active tissues to one another.

Throughout the age range covered in this study the femur may be regarded as consisting of three growing units: the proximal cartilage, the ossified shaft, and the distal cartilage. It is in terms of the developmental behavior of the tissues of these three units that all the growth in the prenatal period must be interpreted. It should be pointed out that the terms diaphysis, metaphysis, and epiphysis, used in standard textbooks and references (e.g., Maximow and Bloom, '52; Ham, '53; Weinmann and Sicher, '47), are of little value in the designation of prenatal growth areas. The areas to which they are applied in postnatal long bones are, at different periods of prenatal development, made up of tissues with differing modes of growth, or even of entirely different tissue types, as in the case of the advance of ossification from the diaphysis into the metaphysis. The rather non-specific terms proximal and distal cartilages and ossified shaft would seem more appropriate than the terms proximal and distal extremities and diaphysis used by Lacroix ('49), particularly because the use of diaphysis without epiphysis is somewhat incongruous. If one accepts this simple major division, both the proximal and distal cartilages may be divided, on the basis of certain anatomical and growth characteristics, into 
three components: intracapsular, extracapsular, and juxtaosseous.

Intracapsular component (fig. 3, stippled areas). The femoral head and those portions of the neck and condyles lying

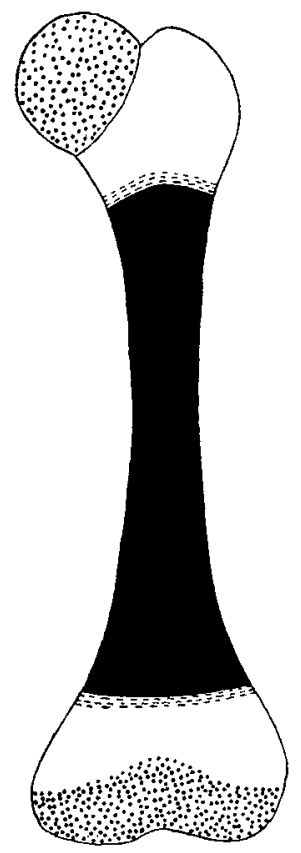

Fig. 3 Growth areas of the prenatal human femur. Represented are intracapsular (stippled), extracapsular (white) and juxta-osseous (dashed) eartilage and ossified shaft (black).

within their respective joint eavities but not covered by capsular reflections may be grouped together under the designation of intracapsular cartilage. From the time when the joint cavities open these areas lack perichondrium. In the absence of the perichondrium, increase in mass of this component must be accomplished by interstitial growth or by proliferation from the connective tissues at the articular margins. Recently the time at which the two articular cavities open has been carefully re-studied. That of the hip was observed to open in human fetuses of $30 \mathrm{~mm} \mathrm{C-R}$ length (Gard- 

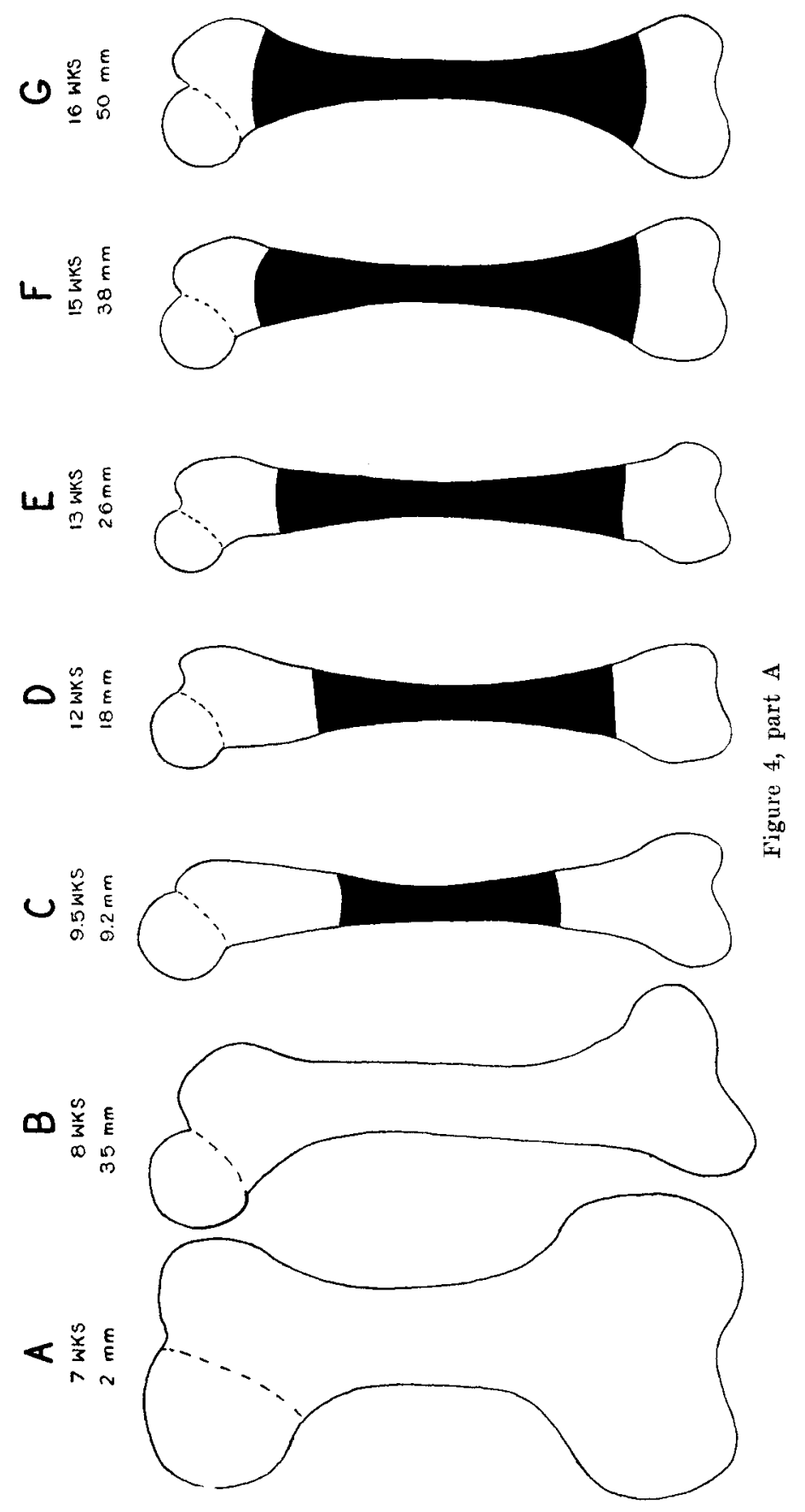

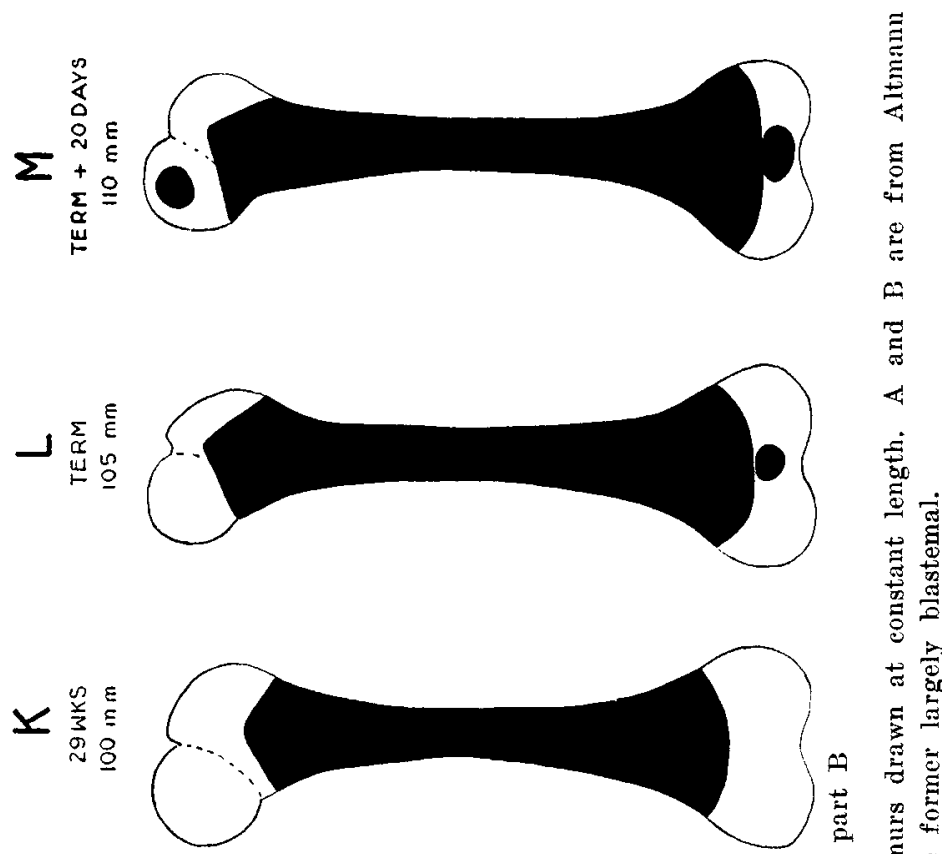

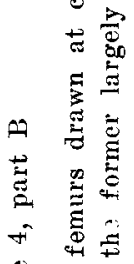

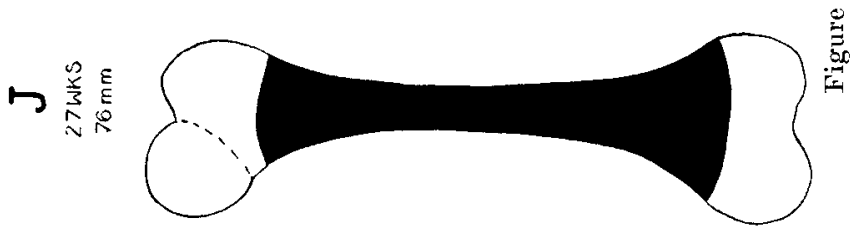

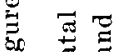
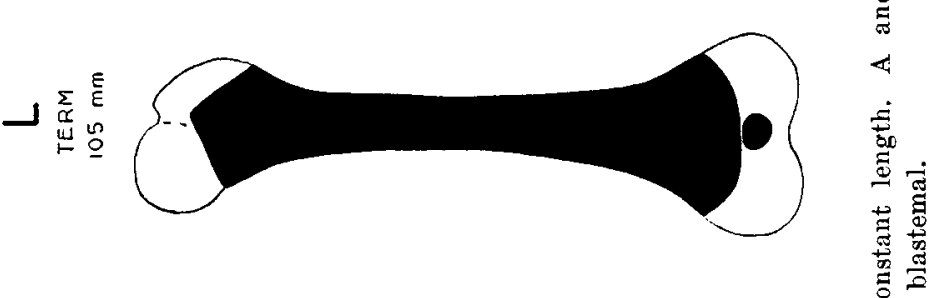

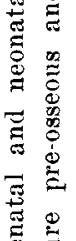

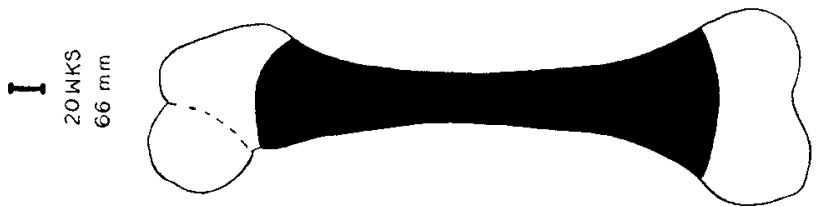

莒苍

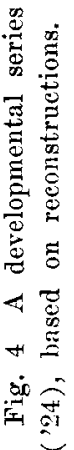

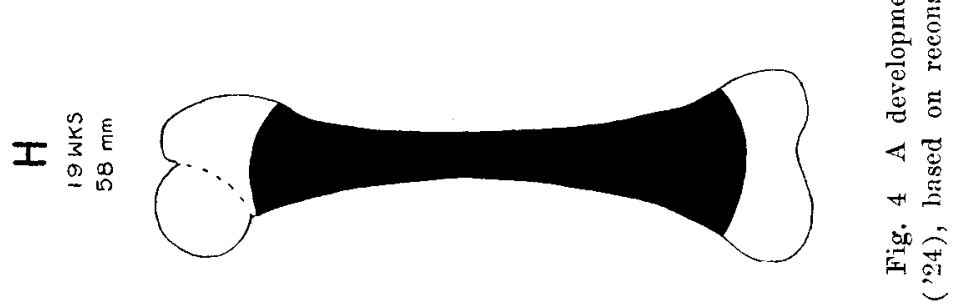


ner and Gray, '50), and that for the knee at 33 to $37 \mathrm{~mm} \mathrm{C}$-R (Gray and Gardner, '50).

The processes of interstitial and appositional growth of cartilage have received only scant attention. Harris and Russell ('33) studied the cartilages of human fetal long bones and mapped mitotic figures. Their illustrations show that interstitial growth, as indicated by the distribution of these figures, is nearly absent in the central region of the cartilages, but is progressively more evident as the peripheral areas are approached. The other possible source of increment to the intracapsular cartilage, proliferation from the connective tissue at the articular margin, has been cited by Weinmann and Sicher ('47); but it would seem that this might be relatively more important in postnatal life when only the thin articular cartilage remains.

Extracapsular component (fig. 3, white areas). The designation extracapsular component covers the remainder of the cartilages except for a narrow zone (juxta-osseous component) adjoining each end of the ossified shaft. The presence of a perichondrium makes possible appositional as well as interstitial growth.

Juxta-osseous component (fig. 3 , lined area). The cartilage against the ends of the ossified shaft may be regarded as the precursor of part of the well defined epiphyseal plate of the postnatal period. Except in microscopic sections, it cannot be distinguished from the extracapsular cartilage. (In this study, no consideration is given that small portion of cartilage overlapped by subperiosteal bone. It should be included, of course, in the juxta-osseous component.) The juxta-osseous cartilage is that in which the cells are arranged in rows parallel to the long axis of the femur, where cellular hypertrophy and final degeneration occur, and where the intercellular matrix is seen to be calcified. This area has been investigated by Haas ('17, '31), Ham ('32), Dodds ('32), McLean and Bloom ('40), and Lacroix ('49). From the present standpoint, two characteristics of this component are of vital importance: orientation of the cell rows or columns and the replacement 
of cartilage by bone, and the fact that the intercellular matrix undergoes calcification. This is a zone of lost potential, as far as interstitial growth is concerned; the proliferation of cells is accompanied by reduction rather than increase in the amount of matrix. As a result, although the tissue organization is modified, there is no growth. In addition, the rigidity of the calcified matrix, which extends at least three or 4 rows in front of the advancing chondro-osseous junction (Dodds and Cameron, '34), precludes even the possibility of increase in diameter by cellular hypertrophy. Finally there is the possibility of a retardation in appositional growth from the periosteum in this zone of transition from perichondrium to periosteum.

Ossified shaft (fig. 3, black area). As in the postnatal femur, the ossified shaft increases in external diameter by apposition, in internal diameter by resorption (Payton, '32; Brash, '34; Aries, '41). The ultimate determiner of its configuration is the cartilage which at either end forms an area of preparation for replacement by bone. Although the osseous tissue is not identical in organization pre- and postnatally, no essential differences in the overall growth process have been demonstrated (Lacroix, '49).

\section{Shaping and proportions}

As a general expression of the relation of femoral growth to body growth, total length of shaft has been plotted against C-R length (fig. 5). Overall length of the femur (an alternative total measurement but subject to the artifacts stated in the section on dimensions) and length of ossified shaft have been plotted against total length of shaft (fig. 6). In order to illustrate changes in femoral proportions, the ratios of the various dimensions to total length of shaft have been shown against increasing length of ossified shaft (fig. 7).

Total length of shaft in this series increases by $0.21 \mathrm{~mm}$ for every millimeter increase in $\mathrm{C}-\mathrm{R}$ length. The variation about the trend is not large (the ratio of the standard error 
of the estimate to the mean, 0.19) considering the variable state of preservation and gross texture of the fetuses. The intersection of the regression line with the abscissa indicates

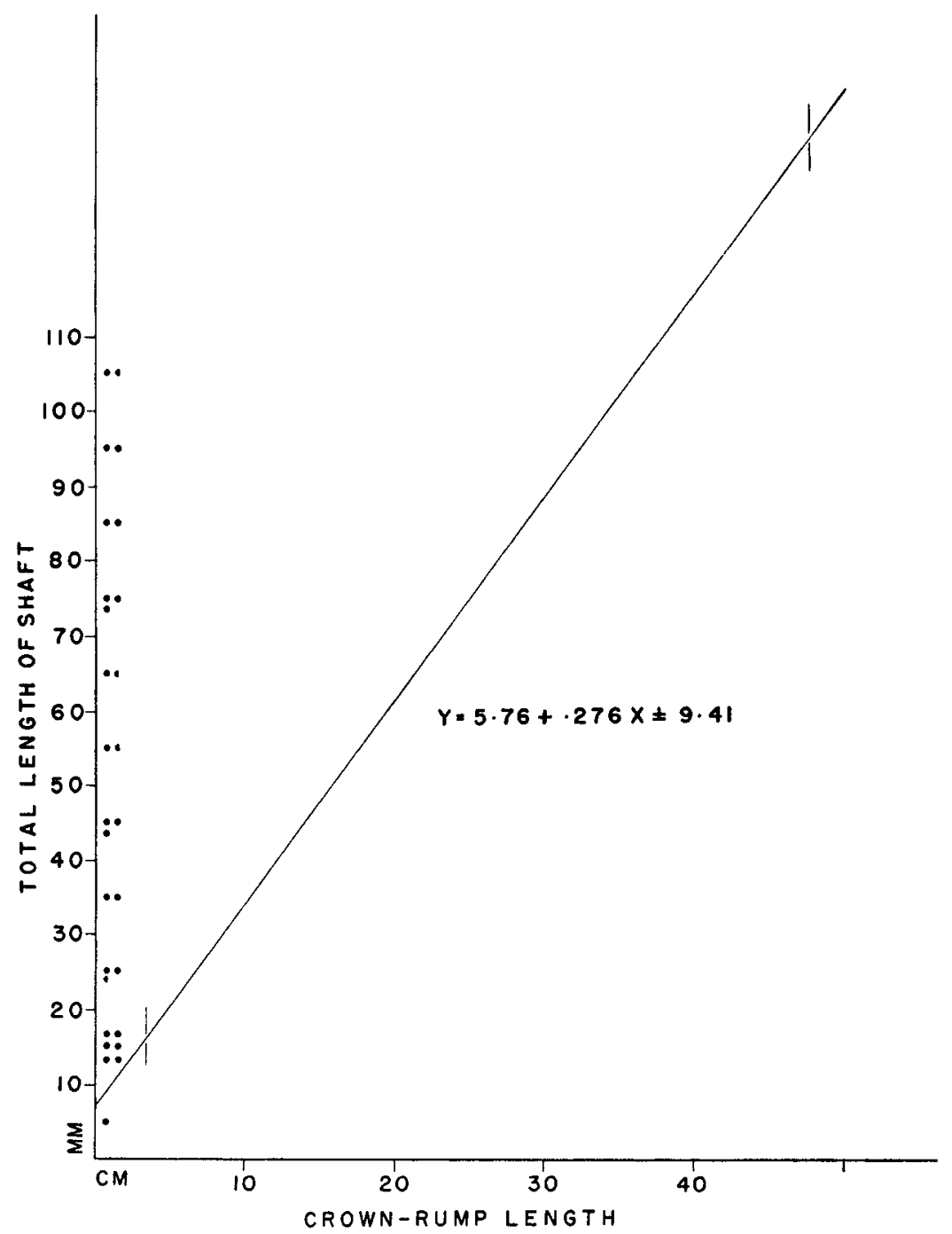

Fig. 5 The regression of total length of shaft upon crown-rump length. The upper and lower limits of the series are indicated by vertical lines and the distribution of specimens within $10 \mathrm{~mm}$ intervals, by black dots (each dot equals two specimens and a half-dot, one). 
that below $31 \mathrm{~mm} \mathrm{C}-\mathrm{R}$ and $8.4 \mathrm{~mm}$ femur length the equation does not fit the growth trend. Although this condition could be due to artifact in fetus measurement, it is probably the result of a more rapid growth trend in the very early stages which is not fitted by the general rectilinear equation. As presented, the material allows at least a fair estimate of the growth of the femur in relation to the body as a whole.

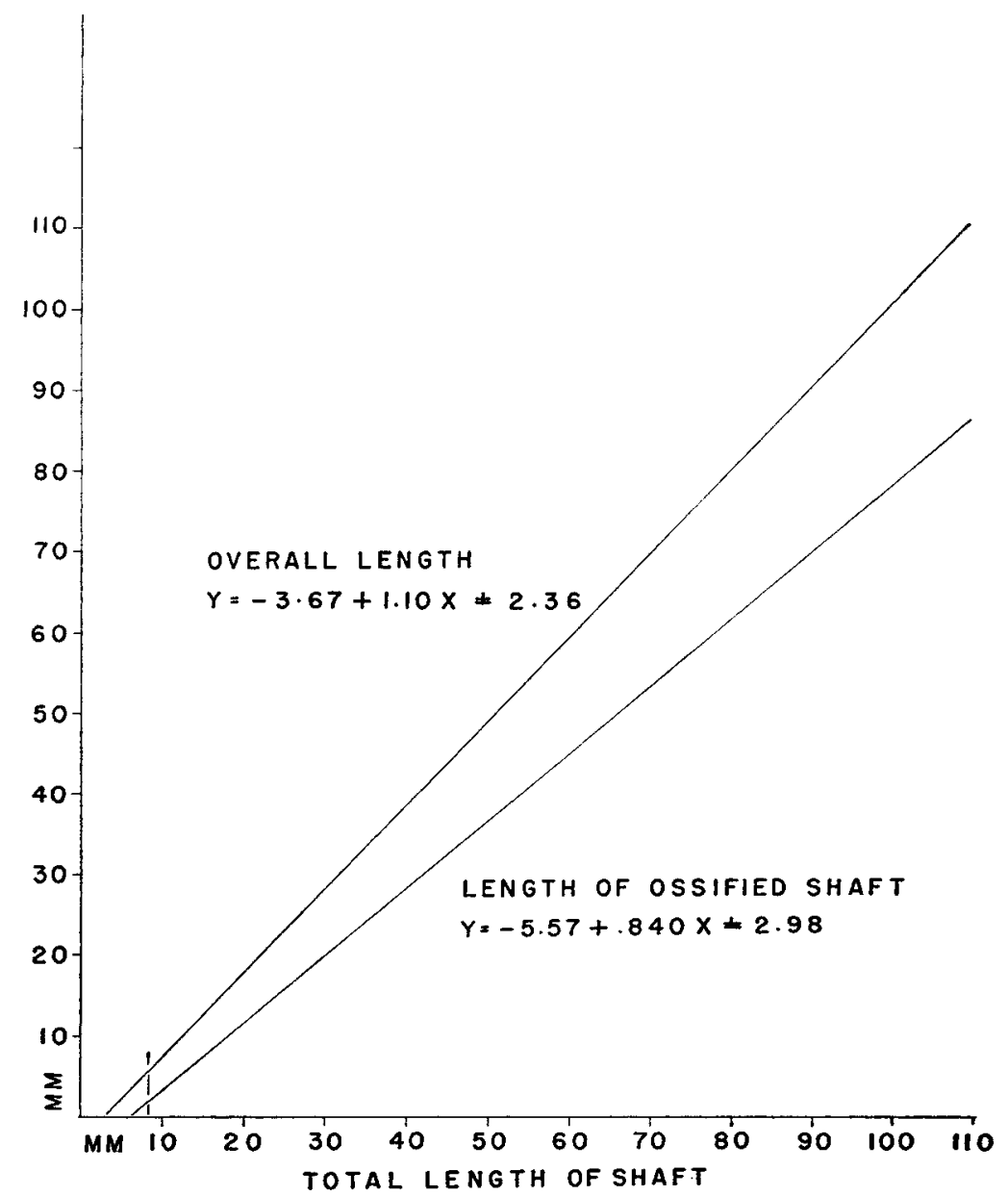

Fig. 6 The regression of overall length of femur and length of ossified shaft upon total length of shaft. Vertical line indicates the lower limit of the series. 
The length of ossified shaft is seen to increase very rapidly relative to total length of shaft, the rate being $0.84 \mathrm{~mm}$ : $1.0 \mathrm{~mm}$. The ratio of the standard error of the estimate to the mean is 0.08 . The estimated length of femur in which ossification would be just initiated is $6.6 \mathrm{~mm}$, short of the smallest femur in this series by $21 \%$. Incipient ossification has been observed in femurs of approximately this size in sectioned embryos.

Relative to length of ossified shaft, the proportion of 6 of the 10 linear dimensions to total length of shaft increase, while those of 4 decrease. (In the following discussion the proportions as well as their increase or decrease are stated in percentage of total length of shaft. Percentage $(\%)$, then, refers to units added or subtracted, and not to percentage change in the sense of multiplication.) The lines of best fit are rectilinear in all but 4 cases. Of these exceptions, the relative increase in the diameter of the chondro-osseous junction is best demonstrated by a parabola, and the other three, the relative decreases in cartilage lengths, by hyperbolae (fig. 7).

The lowest rate of proportionality increase is seen in the mid-shaft region, where the minimum diameter of the shaft increases by but $0.009 \%: 1 \mathrm{~mm}$ increase in length of ossified shaft. Antero-posterior diameter of the shaft has a rate of proportionality increase somewhat higher, $0.014 \%: 1 \mathrm{~mm}$. Over the series this results in an increase of $0.77 \%$ and $1.20 \%$. No explanation can be offered for the fact that the ratio of the standard error of the estimate to the mean is 0.27 for the antero-posterior diameter and but half that, 0.13 , for the minimum diameter of the shaft.

Initially and finally the transverse (bicondylar) width of the distal cartilage is greater in proportion than is that of the proximal cartilage (head-trochanter width). The respective rates of increase are $0.093 \%: 1 \mathrm{~mm}$ and $0.056 \%: 1 \mathrm{~mm}$ of increase in length of ossified shaft. This results in accumulated increases of $7.9 \%$ and $4.7 \%$ over the extent of the series. The larger standard error of the estimate for head- 
trochanter width (ratio to the mean of 0.11 contrasted with but 0.05 for bicondylar width) can perhaps be explained as due in some degree to individual variations in inclination of the head and neck or to other factors inherent in the greater complexity of the proximal end of the femur.

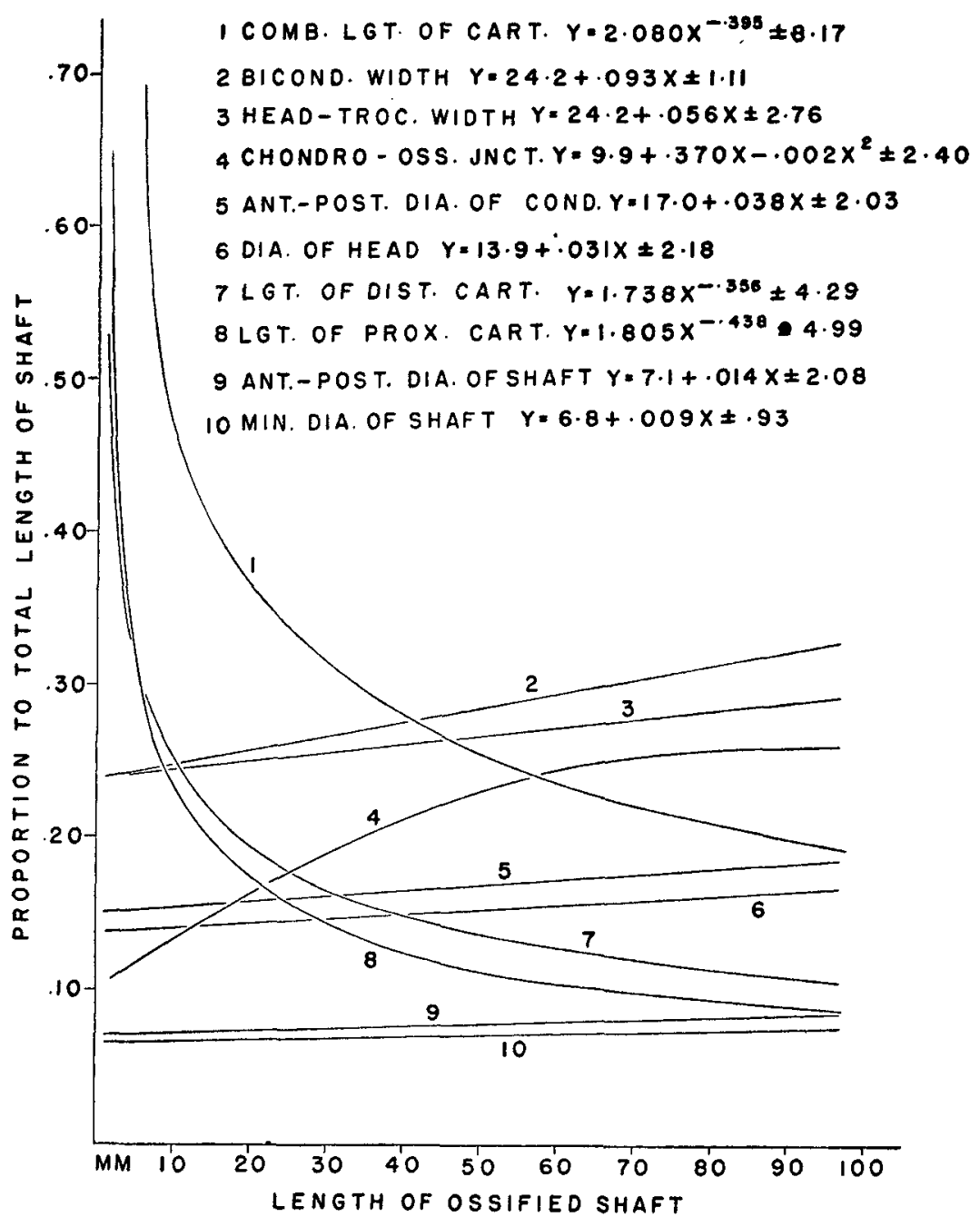

Fig. 7 The regression of femoral proportions upon lengtl of ossified shaft. 
This difference in morphological complexity between proximal and distal cartilages has made it virtually impossible to obtain comparable measurements of the two ends. The second dimension of the proximal cartilage is the diameter of the head. In view of the close relation of femoral head and acetabular shape and size and, as pointed out by LeDamany ('04), the correlation of these characteristics with torsion, the proportionality increase of the head $(0.030 \%: 1 \mathrm{~mm})$ and the standard error of the estimate ( 0.15 of the mean) should obviously be studied in relation to factors other than femur development alone. Within the distal cartilage, the differential growth process is such that, as was also observed by Ingalls ('27), the condylar mass becomes relatively wider in its transverse than in its antero-posterior axis. This is indicated by comparison of rates of proportion change: $0.038 \%$ : $1 \mathrm{~mm}$ for antero-posterior and $0.093 \%: 1 \mathrm{~mm}$ for bicondylar diameters. It would seem that the much larger standard error of estimate for the antero-posterior dimension might be due to either pre- or postmortem compression in that axis with the knee flexed. Indeed, a variable condition of pressure in the flexed knee of the fetus might in some degree be responsible for the difference in rate of proportion change.

All the cartilage lengths, of course, show a decrease in proportion as the length of the ossified shaft increases. At the time when there is a $5 \mathrm{~mm}$ length of ossified shaft, the proportion of cartilage (combined lengths of proximal and distal) in the femur has been estimated to be $69.9 \%$. When the length of ossified shaft has become $50 \mathrm{~mm}$ this has decreased to $25.4 \%$, and when it is $100 \mathrm{~mm}$, to $19.3 \%$. This decrease, best fitted by a hyperbola, is thus most rapid in the beginning, and progressively lessens with increasing length of ossified shaft (fig. 7). The standard error of the estimate has a ratio to the mean of 0.19 .

The proportion of the lengths of the proximal and distal cartilages decreases, of course, in a similar fashion. At the time when there is a $5 \mathrm{~mm}$ length of ossified shaft, the proximal cartilage comprises an estimated $31.6 \%$ of femur length, 
when $50 \mathrm{~mm}, 11.5 \%$, and when $100 \mathrm{~mm}$, but $8.5 \%$. The same stages for the distal cartilage are: $30.8 \%, 13.9 \%$, and $10.6 \%$. Before the time the ossified shaft has attained a length of $10 \mathrm{~mm}$, the distal cartilage begins to exceed the proximal in proportionality to femur length (fig. 7). The respective ratios of the standard error of the estimate to the mean are 0.25 and 0.19 .

The change in proportionality of the diameter of the distal chondro-osseous junction is opposite that for cartilage length, that is, the dimension increases and its course is best fitted by a parabola (fig. 7). At the time when there is a $5 \mathrm{~mm}$ length of ossified shaft, the proportion is $11.7 \%$, when $50 \mathrm{~mm}$, $23.2 \%$, and when $100 \mathrm{~mm}, 25.9 \%$. The ratio of the standard error of estimate to the mean is 0.14 .

In the prenatal femur, or other long bone, any increase in length must be due to increase in length of cartilage, proximal, or distal, or both. The change in the proportion of cartilage and osseous tissue is, then, dependent upon two factors: the rate of cartilage elongation and the rate at which replacement of cartilage by bone occurs. In the present series, every $1 \mathrm{~mm}$ of increase in total length of shaft must be the result of a $1 \mathrm{~mm}$ increase in cartilage length. Since it is estimated that the ossified shaft increases $0.84 \mathrm{~mm}$ for each $1 \mathrm{~mm}$ increase in femur length, it may be said that approximately $84 \%$ of each increment in cartilage length is replaced by osseous tissue while about $16 \%$ of the increment remains as cartilage.

This relationship between rates of cartilage elongation and cartilage replacement by bone is such that bone constitutes approximately $80 \%$ and cartilage $20 \%$ of the length of the femur at term (fig. 7). The femur of a two-year-old is approximately $85 \%$ ossified shaft and $15 \%$ growth cartilage, secondary ossification center, and articular cartilage, whereas in that of a 16-year-old the proportions are $90 \%$ and $10 \%$. Thus the femur of the circumnatal period has nearly attained the relative proportions, of what is usually termed diaphysis and epiphyses, that will persist until maturity. The basis 
for this is seen to best advantage in the distal end of the neonatal femur. When the distal center of ossification appears at or near term it is only a very short distance from the advancing shaft ossification, an average of only $4.5 \mathrm{~mm}$ in the two oldest fetuses in the series. If the growth process characteristic of the fetal period were to continue, the small extent of cartilage remaining between the growing osseous elements would be replaced quickly and there would be "epiphyseal closure" only a short time after birth. This does not occur, of course, and there is thereafter a stabilized condition in the immature skeleton in which each unit of cartilage replaced by bone is compensated for by cartilage proliferation, the cartilage between the shaft and the secondary center remaining approximately at a constant thickness. Although the proximal end of the femur is without secondary centers until later, the same general reasoning may be then applied. Other aspects of the proximal chondro-osseous junction, pertinent to this period, will be discussed under ossified shaft.

The most striking feature of the prenatal development of the femur is the increase in robustness of the ends relative to both total length of shaft and minimum diameter of the shaft. As we have seen, the proportion of bicondylar width to total length of shaft has the greatest rate of change relative to increasing length of ossified shaft. Head-trochanter width, although distinctly less rapid in increase, is second. Their increments in proportion to increase in length of ossified shaft are, respectively, 10.2 and 6.2 times as great as that of minimum diameter of the shaft. In the anteroposterior plane, the relative increase of the condyles is 2.7 times greater than that of the mid-shaft region. (In this plane, it should be recalled, the mid-shaft dimension increases more rapidly and the condylar dimension less rapidly than do the companion transverse dimensions.)

In spite of these comparative values, the actual changes in proportions are not enough to result in the qualitative change in robustness of the developing femur. The essential fea- 
ture of this change is not simply the alterations in the relationship of one linear dimension to another but rather the fact that from a very constricted mid-section the femur flares out progressively to its maximum diameter in the condylar and head-neck region. Differences in the amount of flaring in transverse or antero-posterior planes should not obscure this basic feature. The basic process underlying this morphogenetic modification may be outlined as follows.

The juxta-osseous cartilage constitutes an area where all significant growth potential, in terms of elongation of cartilage and diameter increase, has been lost. This cartilage may be regarded as essentially a narrow zone of lost growth potential moving progressively along the length of the femur away from the middle region of the shaft. This movement is propagated by the continuous replacement of cartilage by bone on one side, and the concomitant addition of cartilage from the extracapsular component on the other side. Ahead of the encroachment of the juxta-osseous zone and the accompanying osseous replacement, the extracapsular cartilage continues to increase in diameter and, of course, in length, as the level occupied by the juxta-osseous zone, for all practical purposes, ceases to do so. This integrated process is responsible for the flaring of the femur away from its midpoint. The rapidly growing cartilage, after alteration and loss of growth potential, is replaced by bone. This replacement occurs faster than the longitudinal growth of the cartilage, but not sufficiently fast to prevent considerable increase in the mass of the cartilage prior to replacement. Since the predominant growth direction at the end of the femur is transverse, the ossified shaft assumes the ever-larger diameter of the cartilage it is replacing. At the minimum diameter of the shaft, which reasonably can be considered to represent the original diameter of the cartilaginous shaft increased by deposition of bone, apposition increases at a low rate. The increase in the diameter of the chondro-osseous junction, on the other hand, is one of the highest rate. 
The proportion of the bicondylar width to total length of shaft at term may be estimated to be $33 \%$ (fig. 7 ). In the two-year-old femur it is $22 \%$, and in a 16 -year-old, $19 \%$. This is a clear indication that the trend of growth, leading; to an increasingly robust femur in the prenatal period, is reversed postnatally. There are again certain features of the distal end of the circumnatal femur which portend this modification in growth. In the late fetal and neonatal femur the diameter of the chondro-osseous junction has nearly come to equal the greatest diameter of the distal cartilage (fig. 4). In this circumstance there is the certain indication of the approaching termination of the previous relationship of juxta-osseous to extracapsular cartilage in which the zone of growth potential loss moved into the mass of rapidly growing cartilage. This is to be correlated with the fact that, as previously discussed, the end of the ossified shaft, in its proximity to the newly-formed distal center of ossification, has reached practically its definitive level relative to the end of the femur. It should be noted too that bicondylar width, the increase in which is used here as an indication of transverse cartilage growth, is never transgressed by the distal chondroosseous junction. Rather, once the junction is stabilized relative to the end of the femur, increase in bicondylar width is dependent upon the transverse growth of the cartilage just behind the junction. This cartilage, largely related to proliferation of the epiphyseal disc, apparently increases in diameter only by appositional growth (Weinman and Sicher, '47).

The process just considered obviously is not the only one in operation in the prenatal femur. Several secondary processes are clearly going on concurrently although they cannot be so readily understood. The whole question of the relative roles of appositional and interstitial growth is not clearly defined. The possibility too of discrete but as yet ummeasured differences in growth rates of very localized areas of cartilages must be recognized. Among such areas are the head which grows progressively out of proportion to the neck, and 
the distal cartilage which grows more rapidly in the mediolateral than in the antero-posterior plane.

\section{Ossified shaft}

Thus far considered as an integral portion of the developing femur, the ossified shaft has certain characteristics that warrant separate discussion.

The ends of the ossified shaft (i.e., chondro-osseous junction) are, in the younger stages of development, neither convex nor concave (fig. 4, C, D). However, as ossification progresses both ends, especially the proximal, become more convex (fig. 4, F, G). The convexity is always and progressively greater in the medio-lateral axis than in the anteroposterior.

In further development the proximal end of the shaft attains, by replacement of cartilage, a diameter progressively greater in the medio-lateral axis than in the antero-posterior. Concomitantly, convexity in the medio-lateral axis increases rapidly, while that in the antero-posterior axis undergoes almost no increase. By the time the end of the shaft has progressed to a level superior to the site of the lesser trochanter, this convexity has altered to a rather distinct angulation (fig. 4, K, L). In this manner the proximal end of the shaft (in terms of growth, the chondro-osseous junction) becomes divided into two major planes, neither of which even approaches a perpendicular relation to the long axis of the femur. The medial plane underlies the cartilage of the neck; the lateral plane underlies the cartilaginous greater trochanter (fig. 4, M). The angulation continues to increase and the neck segment advances into the cartilage far enough so that the two planes become discrete early in the postnatal period. Although it is difficult to determine exactly, it appears that in later development, bone from the shaft never grows quite a third of the way toward the apex of the greater tronchanter; replacement by bone from the shaft, on the other hand, does occur throughout the neck and the basal half (or a little 
lesss) of the head. The proximal centers of ossification arise postnatally. That of the head appears in an early postnatal specimen in the present series, but that of the trochanter is delayed well beyond the age range of this study.
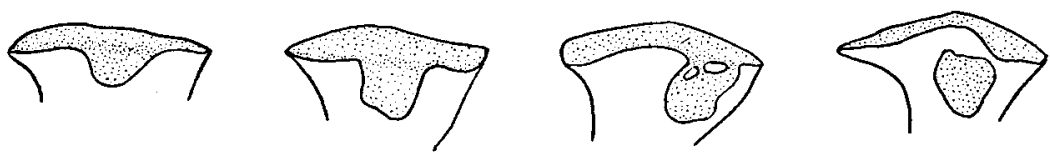

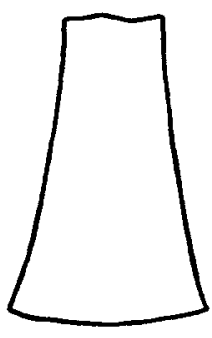

A

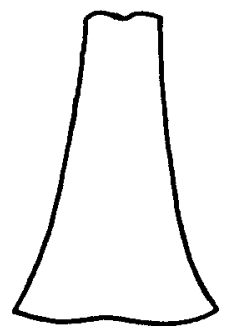

B

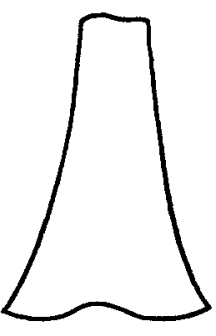

C

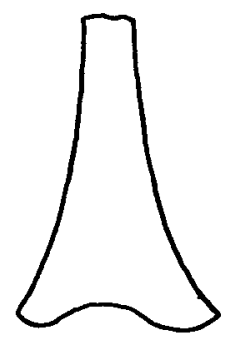

D

Fig. 8 Developmental clianges in shaping the proximal (above) and distal (below) ends of the ossified shaft. Posterior view of the proximal end illustrates progressive deviation of end of shaft into two planes, and the detachment of the chondro-osseous junction of the lesser trochanter. The distal ends reveal the increasing concavity. Secondary centers of ossification were present in the last two. Total length of shafts: A, $25.0 \mathrm{~mm} ; \mathrm{B}, 54.4 \mathrm{~mm} ; \mathrm{C}, 105.3 \mathrm{~mm}$; D, $160 \mathrm{~mm}$. The left side is medial.

Except in its basal portion the lesser trochanter remains cartilaginous throughout the fetal period. The small chondroosseous junction at its base, however, does not arise by angulation of a portion of the proximal end of the ossified shaft away from the major plane, as described for the greater trochanter. Rather, it appears that as ossification of the proximal end of the shaft progresses past the base of the cartilaginous lesser trochanter an area of preparation for osseous replacement comes into existence in the basal part, 
and a small chondro-osseous junction is formed perpendicular to the main proximal one. The first manifestation of this can be observed on the bare ossified shaft in a small, low triangle the base and surface of which are continuous with, and at right angles to, the edge of the proximal end of the shaft (fig. 8, A-B). As the shaft elongates, this roughly triangular platform becomes detached from the end of the shaft; it is entirely detached by the time the proximal end of the shaft first evidences a definite angulation into trochanteric and neck planes. Thereafter, the base of the trochanter maintains its position relative to the end of the shaft.

Although the proximal end of the ossified shaft has thus advanced into the complex region of the neck and trochanters and has undergone the alterations in configuration just discussed, the distal end also has changed, though in a less radical manner. In the process of replacing the cartilage of the lower shaft, the distal end of the ossified shaft widens greatly on its medio-lateral axis and much less so on the antero-posterior. The distal end plane, like the proximal, is at first flat, but becomes progressively more convex (fig. 8, A-D). Convexity increases as the shaft elongates, until the end has attained a level nearly at the site of the future distal center of ossification. In ossified shafts longer than approximately $75 \mathrm{~mm}$ (overall length of femur, about $92 \mathrm{~mm}$ ) it can be observed that the medio-lateral convexity has been lost and that, instead, there is a depression in the middle of the end plane (fig. 8, B-D). It appears from this that there is a falling off of the rate of elongation of the ossified shaft, i.e., a reduction in the rate of cartilage replacement, in the area immediately adjacent to the site of the distal ossification, about a month before the actual distal ossification center appears. The replacement of cartilage by bone progresses at a higher rate around this area, particularly medially and laterally, and the convexity is replaced by an irregular concavity.

Comparison of the ossified shaft of prenatal and postnatal femurs makes it clear that there must be a striking difference 
between the two in the proportion of growth in length that occurs from either end. Throughout more than half of the fetal period the chondro-osseous junctions, although they undergo changes in curvature, are approximately perpendicular to the longitudinal axis of the shaft. Assuming that cartilage at the ends of the shaft is replaced by bone at the same rate, on the average, the two ends would contribute equally to elongation. It has been pointed out (Keith, '19; Weinmann and Sicher, '47) that growth of the postnatal femur in length occurs mainly from the distal epiphyseal disc because it is the only one of the 4 discs of the femur that lies perpendicular to the shaft's axis. In this position, all of its contribution to length is effective. The remaining dises contribute only to the elongation and enlargement of their respective processes, except that some addition to length can be gained with the incorporation of the basal areas of the angulated neck and greater trochanter by modelling resorption. In the early and progressive deviation of the proximal chondro-osseous junction into neck and trochanteric planes there can be seen a possible origin of the inequality of contribution to the length of the femur. The process of deviation is a gradual one and the results are probably not critical until some time after birth, when deviation is more or less complete and the proximal chondro-osseous plane has separated into two distinct entities.

The foregoing discussion rests on the assumption that equal rates of cartilage replacement occur at the ends of the femur, but contribute to growth with unequal effectiveness. It is also possible that the rate at one end, as a regular developmental characteristic, exceeds that at the other.

The inequality of contribution to elongation due to differences in actual growth rate at the two ends of a long bone has been extensively considered (see Keith, '19, for survey of early work on this topic). In particular reference to the femur, Payton's ('32) investigation of madder-stained bones in the pig showed that the adjacent ends of the tibia and femur grow more rapidly than the opposite ends. Harris ('26, 
'31), working with roentgenograms of children, and Aries ('41), with alizarin-stained rat bones, agreed with this. Bisgard and Bisgard ('35), though supporting the findings of Payton in their results from the postnatal period, observed that in the prenatal period, as indicated by measurements from phosphorus deposition lines, there is a more nearly equal contribution of growth from the ends of the femur; this was found to be particularly true of the early prenatal period.

Fundamental as it is to the study of inequality of contribution of growth, the attempt to discover a natural fixed point in non-stained or otherwise non-experimental bones has not yet yielded a completely satisfactory result. Digby ('16), who examined adult human long bones, concluded that the nutrient artery represents the vascular portion of the original periosteal bud and that the site of the original ossification (endochondral) from which growth progresses in either direction could be located at the intersection of the axes of the nutrient canal and the shaft. He presented data to show the proportions of the shaft lying on either side of this reference point.

Although there has been general agreement that the nutrient artery and its canal are closely related to the initial ossification, more recent investigators have contested the conclusions and even the observations referred to above. Although Bisgard and Bisgard ('35) supported Digby's conclusions, Payton ('34) took strong issue with the concept of the fixed central point after finding that in his series of madderstained pig bones the nutrient foramen appeared to vary in position independent of shaft growth. Although offering no substitute explanation, Hendryson ('45) questioned the validity of Digby's conclusion and reported that in his own series of human bones the variation about the mean position for the central point was so great as to cast doubt upon its utility as a landmark from which to measure; Lütken (' 50 ) published essentially similar observations. 
Of the previous investigators, only the Bisgards treated the prenatal period and that in the goat. In an investigation such as the present one, restricted as it is to gross morphology, only slight additions can be made to knowledge of these questions. Nevertheless, some of the facts to be presented may be of value because they are concerned with the prenatal period of human skeletal development, which has been much less intensively studied. Roentgenographs were made of the lateral projections of a series of 10 femurs evenly spaced over the series. Upon enlarged tracings of these pictures the central point was determined in the manner of Digby and Payton. It was observed that the point of intersection of the axis of the nutrient canal with that of the medullary cavity was in all cases almost exactly at the narrowest diameter of the medullary cavity. In two cases there were double nutrient canals, one pointing inward and distally and the other inward and proximally. In these cases the central point was considered to be midway between the two points of intersection. In these 10 femurs the proportion of the total length of the ossified shaft between the proximal end and the point of intersection was $48.6 \%$ on the average (standard deviation, 2.21). The maximum was $52 \%$, the minimum $44 \%$. The youngest (smallest) specimen had a value of $50 \%$, the oldest, $47 \%$.

These findings, although from a relatively small series of femurs, suggest that, at least in the fetal period, the point of intersection may well be a central point on either side of which the ossified shaft elongates. The fact that the point nearly coincides with the narrowest diameter of the medullary cavity is important; that diameter, in the sharply constricted cavity of fetal long bone may in itself be considered a "central point," since the narrowest internal diameter of the growing femur should coincide with the original central portion of the early periosteal collar.

The decrease in the percentage of the ossified shaft proximal to the central point, however small, is of interest. In the smallest femur in the series $(18.3 \mathrm{~mm}$ total length of 
shaft) the $10 \mathrm{~mm}$ ossified shaft is equally divided by the point. In the largest specimen $(109 \mathrm{~mm})$ the $84.3 \mathrm{~mm}$ ossified shaft is divided into $40.0 \mathrm{~mm}$ proximal and $44.3 \mathrm{~mm}$ distal.

\section{Angular dimensions}

Up to this point the emphasis has been on the developmental characteristics of the femur that can be attributed directly to growth per se, that is to say, manifestations of cellular activity and tissue increase along certain genetically determined lines. As has been shown by experiments in which long bones were cultivated in vitro, this inherent pattern is rather rigid (Murray, '36). Yet the femur or any other long bone is acted upon, in its normal environment, by the circumjacent connective tissues and muscles, the presence of which sets up pressures and tensions. It is affected, also, by the postural habits of the organism, and, quite likely, in the fetal period, by the confining action of the uterine wall. Within poorly defined limits all such forces can be effectively countered by the inherent configuration and substance of the femur; beyond these limits there is an adaptation of the inherent configuration to meet the individual situation.

Precisely how much adaptation to the individual environment is hidden in what one usually terms the inherent developmental pattern is a question. It does not appear that there has ever been a quantitative study of the exact differences existing between series of long bones grown normally and ones grown in vitro. There are, however, several femoral characteristics that, because of their high degree of individual variation, can be readily classified as functional adaptation as such, or perhaps as inherent characteristics with a superimposed variation in the individual adaptation. These characteristics are all such as can be expressed in angles. In the order of their discussion, they are torsion, inclination, and obliquity. Although it might at first be considered that the angular dimensions cannot be measured as accurately as, for example, bicondylar width, it should be 
noted that obliquity, which has the largest standard error of the estimate of any in this study, is determined from landmarks as easily and as reliably located as those for the bicondylar dimension. Approximately the same may be said for torsion, which has the second largest standard error of the estimate. Finally, and most critically, individual variation of the angular dimension is so marked that it can be recognized by direct inspection.

As far as I am aware, this is the first time that these three angular dimensions have been studied quantitatively in the same series of fetal specimens. In previous studies of one or another of these characteristics there has almost always been offered some form of explanation of supposed causative factors. None of these explanations, whether they point to factors inherent in the femur, or to extraskeletal factors, or both, seems at all probable when applied to all three developing characteristics. It seems obvious that all must be considered as a complex, and for that reason no explanation is either cited or suggested at this time.

Torsion. Values for torsion of the adult femur, that is to say the angular displacement of the head and neck anterior: (anteversion or positive torsion) or posterior (retroversion or negative torsion) to the frontal plane, have been reported since before the beginning of this century. Mikulicz (1879) presented data from which Elftman ('45) computed a mean of $11.67^{\circ}$. LeDamany ('03a, '03b) showed a variation between left and right femurs with an average of $11.33^{\circ}$ on the right and $14.07^{\circ}$ on the left. Pearson and Bell ('19) found roughly the same condition: $11.63^{\circ}$ for the right and $14.71^{\circ}$ for the left. However, the opposite variation was observed by Ingalls ('24), whose series had an average of $11.76^{\circ}$ on the right and $9.73^{\circ}$ on the left. Elftman ('45) gave a bilateral average of $11.23^{\circ}$. Kingsley and Olmstead ('48) derived a bilateral average of $8.02^{\circ}$, with $7.47^{\circ}$ for the left and $8.54^{\circ}$ for the right. As illuminating as the means are the variations expressed by the standard deviations computed by several of the authors: Pearson and Bell, 8.80; Ingalls, 7.87; 
Elftman, 6.21, and Mikulicz (computed by Elftman), 9.61. Ingalls, commenting on the femur as a whole, stated that the differences between left and right are very small and that, of the two, the right seems to be slightly more constant.

There are, naturally, differences in the technique of measuring torsion employed by the various investigators, but these differences do not appear significant. Certainly there is not enough difference in method to account for the range within and between the reported series of measurements.

A highly significant feature of human femoral torsion is the mamer in which it progresses through ontogeny. Altmamn ('24) showed that non-human femurs, although possessing torsion to an extent varying with the taxonomic group, do not undergo a reduction of torsion after birth.

Although the degree of torsion present in the femur of the luman infant, child and adolescent has been well enough investigated to admit generalization, information concerning its sequence is still far from complete. Mikulicz (1879) presented the following values for 38 specimens: 0 to 2 years (14 specimens), $-19^{\circ}$ to $39^{\circ} ; 2$ to 5 years $(13),-8^{\circ}$ to $22^{\circ} ; 5$ to 18 years $(11), 4^{\circ}$ to $28^{\circ}$. LeDamany ('03a) gave data on the left and right femurs of 8 term fetuses. Computations from his data yield an overall mean of $35^{\circ}$, with a range of from $21^{\circ}$ to $50^{\circ}$. A fairly well distributed series was presented by Rogers ('31, '34), from whom the following means and ranges were adapted: 18 specimens, 6 months to 4 years, $38.5^{\circ}\left(15^{\circ}\right.$ to $\left.57^{\circ}\right) ; 26,4$ to 8 years, $23.5^{\circ}\left(8^{\circ}\right.$ to $\left.35^{\circ}\right) ; 54,8$ to 12 years, $20.0^{\circ}\left(8^{\circ}\right.$ to $\left.38^{\circ}\right) ; 2,12$ to 14 years, $16.0^{\circ}$. Kingsley and Olmstead ('48) have published findings on torsion in 32 infants and children, two to 15 years of age. Their average for the left side was $16.4^{\circ}\left(-4^{\circ}\right.$ to $\left.38^{\circ}\right)$ and for the right, $17.9^{\circ}\left(5^{\circ}\right.$ to $\left.33^{\circ}\right)$. The bilateral average was $17.2^{\circ}$.

From these data it is apparent that femoral torsion is somewhat more variable in the early postnatal period than in the adult. From a circumnatal value of $30^{\circ}$ to $40^{\circ}$ there is 
a reduction in torsion toward the average adult value of approximately $12^{\circ}$.

During the prenatal period, quite the opposite trend is seen. Altmann's ('24) reconstructed femurs of less than $5 \mathrm{~mm}$ overall length had a torsion range as follows: $2 \mathrm{~mm}$ femur, $-10^{\circ}$ (side not given) ; $2 \mathrm{~mm}$ femur, $-9^{\circ}$ right, $-6^{\circ}$ left; $3 \mathrm{~mm}$ femur, $-4^{\circ}$ right, $-9^{\circ}$ left. The embryo lengths were, respectively, 17, 19.7, and $28.5 \mathrm{~mm}$ (apparently C-R).

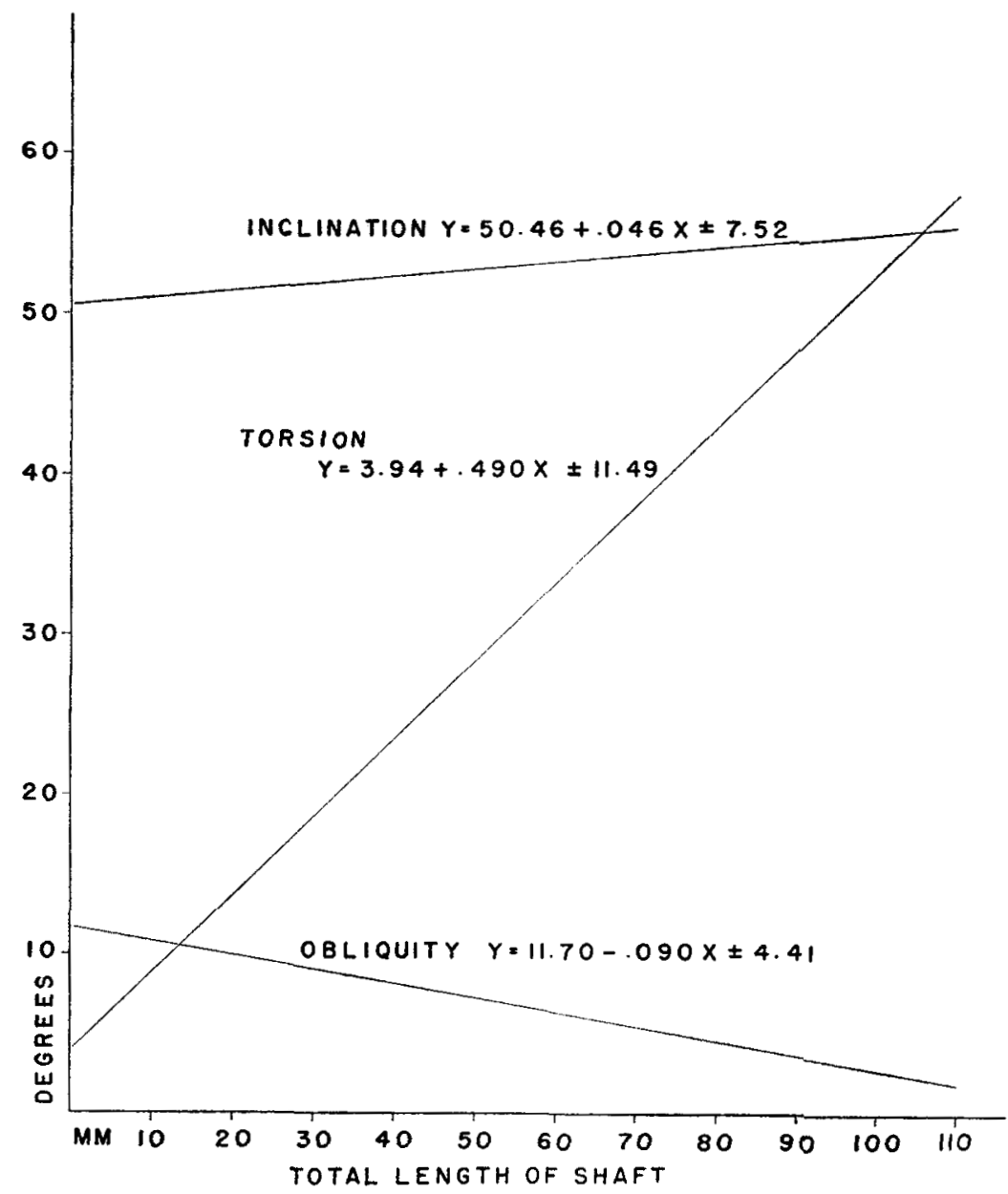

Fig. 9 The regression of the angular dimensions upon total length of shaft. 
Friedländer ('01) stated that there is about $-10^{\circ}$ torsion at the time the femur becomes cartilage. Pitzen ('23), in three fetuses under $29 \mathrm{~mm}$ length, found torsion values of $-4^{\circ},-22^{\circ}$, and $-15^{\circ}$. From these data it appears that the initial torsion is negative and that the femur is initially differentiated with that orientation.

Utilizing the equation (fig. 9) describing the line of best fit for the torsion-total length of shaft relation of the present series, it may be estimated that torsion increases approximately one-half as rapidly as does femoral length $(0.49: 1)$. The ratio $(0.43)$ of the standard error of estimate to the mean is second in magnitude only to that of another angular dimension, obliquity. Marked individual variation is, therefore, as much a significant feature of torsion as its ontogenetic increase and subsequent decrease, and is worthy of closer scrutiny. Figure 10 illustrates the range in torsion values, by $5 \mathrm{~mm}$ intervals of total length of shaft, for the femurs of this series and for those of Altmann ('24), Brandt ('28), and deCuveland ('50). Of previous studies of femoral torsion, only these have presented the femur lengths corresponding to the torsion values. Because there appeared to be no significant difference in the techniques used in collecting the 4 sets of data, the depicted ranges may be considered indicative of those possible over the femur length range studied. The findings may be summarized as follows. In the present series, the greatest negative value found was $-26^{\circ}$ in a $14.4 \mathrm{~mm}$ femur (C-R length, $63 \mathrm{~mm}$ ), and the greatest positive one $64^{\circ}$ in a $99.5 \mathrm{~mm}$ femur (C-R length, $310 \mathrm{~mm}$ ). The smallest fetus (C-R length, $31.0 \mathrm{~mm}$ ) had $7.5^{\circ}$ torsion in an $8.4 \mathrm{~mm}$ femur; the single infant (C-R length, $485 \mathrm{~mm}$ ), $52^{\circ}$ in a $110.6 \mathrm{~mm}$ femur. The arbitrarily chosen, but typical, adult average of $11.23^{\circ}$ (Elftman, '45) is exceeded in $80 \%$ of the cases (40 of 50 femurs). The 10 specimens in which torsion was less than the adult value averaged only $20.1 \mathrm{~mm}$ in total length of shaft (range, $8.4-49.6 \mathrm{~mm}$ ) and the fetuses from which they were collected had an average of only $71.8 \mathrm{~mm}$ in C-R length $(31.0-163.0 \mathrm{~mm})$. 


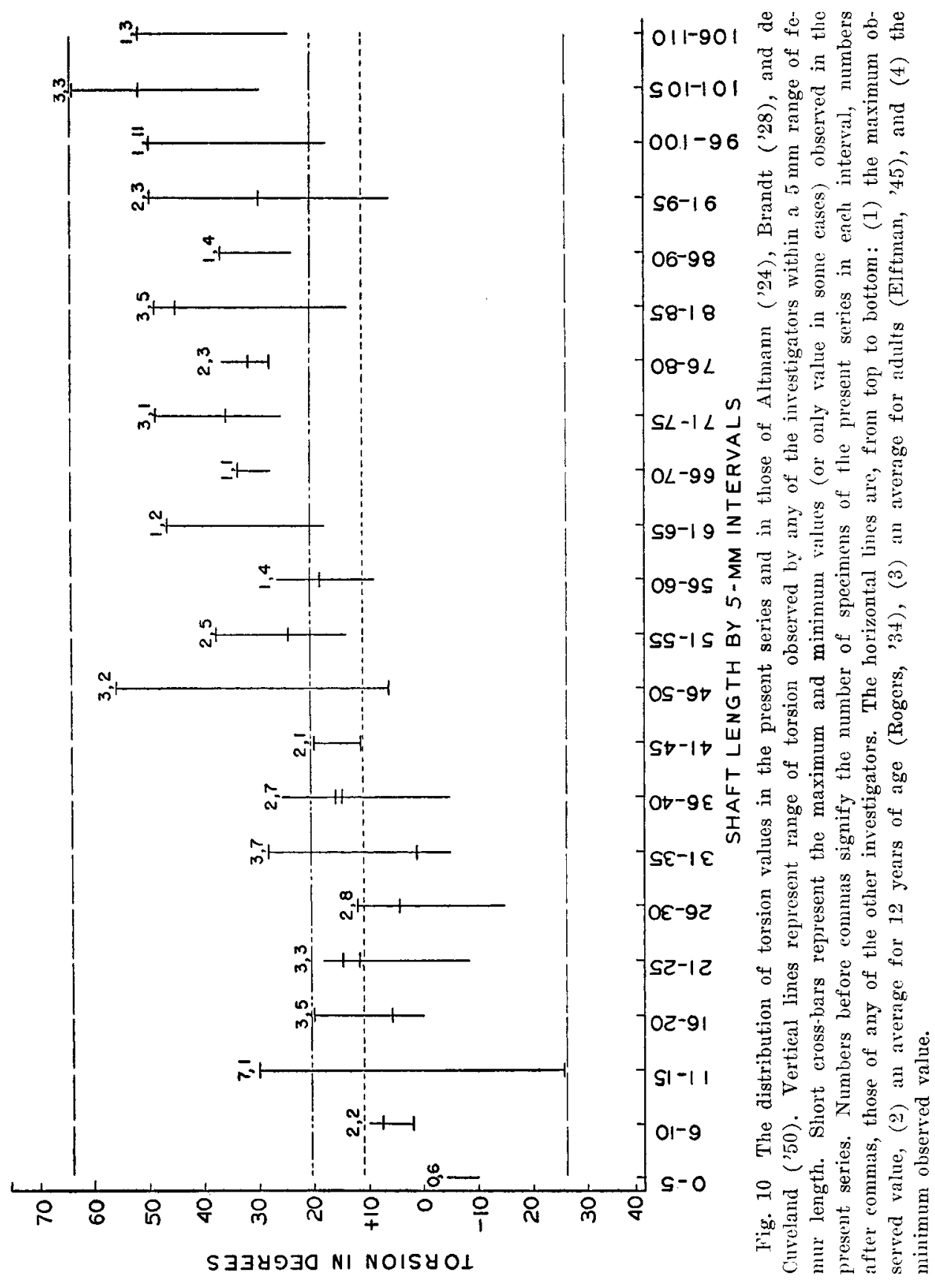


For the combined series (fig. 10), the following observations appear pertinent. The greatest value for torsion exceeds the adult average in $91 \%$ of the $225 \mathrm{~mm}$ groups, and an average for 12 years of age (Rogers, '34) is exceeded in $73 \%$ of the groups. The least value in the range is less than the adult average in 50\% of the groups and less than the 12 -year-old average in $73 \%$. In all the groups above $50 \mathrm{~mm}$ total length of shaft the average torsion exceeds that of the adult, whereas this occurs in only $33 \%$ of those groups below $50 \mathrm{~mm}$. Conversely, the least value of torsion is less than the adult value in $23 \%$ (three of 13 ) of the groups above $50 \mathrm{~mm}$ total length of shaft but is less than the adult value in $88 \%$ ( 8 of 9 ) of the groups below $50 \mathrm{~mm}$.

From these data it is obvious that torsion, at any given fetal level, shows a very high degree of individual variation and that its increase in the prenatal period is even greater than its postnatal decrease. In addition, it is seen that increase in torsion is characteristic of the whole of the prenatal period. This fact, although demonstrated by others, is not indicated by LeDamany, whose work especially has influenced orthopedic thought concerning torsion.

Pitzen ('23) found that torsion was not restricted to the proximal region of the fetal femur but was present throughout its length. In order to determine this in the present series, 4 femurs of distinctly different degrees of torsion were sectioned and the torsion of each section determined as accurately as possible. Femurs A to D (table 1) represent low, moderate, and relatively high values of positive torsion, and high negative torsion, respectively. The technique for handling these selected specimens was more elaborate than that described for the series as a whole. They were decalcified in $1 \% \mathrm{HCl}$, washed, and infiltrated with a $10 \%$ warm gelatin solution, then embedded in $25 \%$ warm gelatin. Care was taken to have the condyles and trochanter on a level with the bottom of the block, that is, the femur was orientated relative to the base of the block in the same manner as it was to the turntable on which previous photographs were taken. 
The gelatin was allowed to set in cold air, and was further hardened overnight in a $10 \%$ solution of formalin. Sectioning was done with a razor at 5 levels: (1) through the head and neck, (2) through the lesser trochanter, (3) at mid-length, (4) through the condyles, and (5) at a point between the last two.

A protractor was so arranged that its center coincided with that of a cross-line on a counting ocular for a compound microscope. The cross-line was adjusted, by rotation of the ocular and manipulation of the mechanical stage, so that it was

TAPLE 1

Torsion (in degrees) at different levels in four femurs (see text for explanation)

\begin{tabular}{|c|c|c|c|c|}
\hline FEMCRS & A & $n$ & $\mathrm{C}$ & $\mathrm{D}$ \\
\hline Fenutur in toto & 1.0 & 8.0 & 30.0 & -26.0 \\
\hline Levels 1 & 0.0 & 7.0 & 28.5 & -19.0 \\
\hline 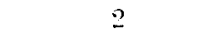 & 0.0 & 5.5 & 22.0 & -11.0 \\
\hline 3 & 0.0 & 0.0 & 14.0 & -6.0 \\
\hline 4 & 0.0 & 0.0 & 6.0 & $\ldots 0.5$ \\
\hline 5 & 0.0 & 0.0 & 0.0 & 0.0 \\
\hline
\end{tabular}

parallel with the base of the section on a slide. A zero reading was taken on the protractor. The section was then moved on the mechanical stage until the cross-line, by further adjustment, appeared to pass through the major longitudinal and transverse axes of the section of cartilage or bone. The torsion at the station was read as the difference between the first and a final reading of the position of a fixed needle on the protractor. It must be admitted that, by this technique, one is not always measuring equivalent things at all levels of a femur, for torsion thus determined is based upon the shape of the external outline of the section. Nevertheless, approximately the same thing is being measured at any one level in all 4 femurs and the torsion in a given section is higher or lower depending upon whether the femur in question has a greater or lesser degree of torsion at the proximal end. The ralues are listed in table 1. 
The ralues just given make it evident that in the femur torsion is not a feature restricted to a localized area as is the case in the humerus. As was pointed out by Krahl ('4i, '48), torsion in the humerus occurs at the junction of the diaphysis and the proximal epiphysis. In the femur, on the basis of the work of Pitzen and the above values, torsion is a total characteristic, present throughout most of the shaft.

Inclination. Almost nothing concerning the prenatal state of this relationship was found in the literature. Friedländer ('01) noted that the angle of the head and neck to the femoral shaft is generally highest in very early fetuses (i.e., the neck is more nearly in line with the shaft). Pitzen ('23) commented that in the $11 \mathrm{~mm}$ human femur inclination amounts to $130^{\circ}$ and that there is apparently little change in this angle during the fetal period. It has been indicated by Strayer ('43) as well that the head and neck deviate from the shaft very early in development. It is indeed surprising that the angle of inclination has been ignored in almost all the studies of early torsion development, especially considering the fact that both angles are, superficially at least, measurements of the same anatomical complex in different planes. Compared with torsion, inclination in the adult femur again has been less well examined. Humphry (1888) stated an adult value of $124^{\circ}$, Pearson and Bell ('19), 126 , Ingalls ('24), 129.6 ${ }^{\circ}$ and Pick et al. ('44), $126.40^{\circ}$.

Perhaps the major reason for the sparsity of data on fetal inclination lies in the difficulties related to its determination, particularly in smaller fetuses. In the present study, no procedure could be devised that would allow the femurs to be so manipulated as to permit photographing the head-neck region perpendicular to the plane of inclination without jeopardizing the practicability of the overall technique. As a result, the degree of torsion present in a given specimen will affect the amount of inclination seen in a frontal photograph. What is presented here, then, is apparent inclination and, other factors being equal, the head-neck axis will appear more in line with the shaft in a specimen with high torsion. 
The present inclination values can be considered, therefore, as subject to two variables: the probable high individual variation in actual inclination and the artifact introduced by equal or greater variation in torsion.

In this study, inclination has been measured as an angle which opens superior to the head-neck axis rather than inferomedially as is traditional in soteometric technique (Martin, '28, for example). This was done simply because it takes cognizance of the direction of the change and because it demonstrates the alteration from the primordial condition in which the head-neck and shaft axes are most nearly in a straight line (blastemal stage). To correct the present equation to the traditional sense, the estimated values should be subtracted from $180^{\circ}$. The positive regression wonld then, of course, become a negative one.

Although presented with definite reservations, the data on inclination in this series are not without value. From the equation (fig. 9) it can be estimated that inclination increases approximately $0.04^{\circ}$ for every millimeter increase in total length of shaft. When, however, one considers the relationship of apparent inclination to the highly variable torsion, it appears obvious that the actual increase is greater than that estimated and that the relatively low standard error of estimate (ratio to mean, 0.14) is perhaps fortuitous.

Obliquity. Nothing was found in the literature concerning the angle of obliquity during the period of fetal development, excepting Pitzen's ('23) observation that the angle of the infracondylar plane to the axis of the femur is greater throughout most of the prenatal period than it is in the postnatal. The illustration of the reconstructions of Bardeen ('05) and Altmann ('24) also indicate this. Neither of these authors discuss the point. Ingalls ('27) stated that obliquity is less at term than in the adult femur. For the adult, Pearson and Bell ('19) gave figures of, for right, $8.69^{\circ}$, for left, $11.59^{\circ}$. Grossberg ('24) had higher values for right $\left(10.32^{\circ}\right)$, but lower for left $\left(8.70^{\circ}\right)$, while Ingalls gave right and left figures of $8.63^{\circ}$ and $8.70^{\circ}$. 
In the present series, obliquity (fig. 9) was found to decrease at the rate of $0.09^{\circ}$ for every millimeter increase in total length of shaft. It was rather surprising that this dimension exhibited the largest standard error of the estimate (ratio to mean: 0.61) of any studied, particularly in view of the amount of attention that has been given in the literature to variation in torsion. One femur $(13.2 \mathrm{~mm})$ has a negative obliquity of $-3.0^{\circ}$. The smallest femur had an angle of $9.0^{\circ}$, the largest, $3.0^{\circ}$. The highest value was $28.0^{\circ}$ (14.9 $\mathrm{mm}$ femur), the lowest, $1.0^{\circ}(76.2 \mathrm{~mm}$ femur). It appears that the lateral condyle increases in mass more rapidly than the medial (Ingalls, '27). Although this points to the possibility of a "simple" growth factor in lowering the infracondylar plane on the lateral side and so decreasing the angle, it affords no explanation of the extremely high individual variation in the angle. If the inherently greater rate of growth of the cartilage of the lateral condyle is responsible for the decrease in the angle, this factor must be modified by others of approximately the same range of magnitude as those operating in the case of torsion.

According to the determined equation for obliquity in this series, femurs of less than $25 \mathrm{~mm}$ total length of shaft exceed the average of the adult values cited above $\left(9.42^{\circ}\right)$. Femurs of a length greater than $25 \mathrm{~mm}$ should have angles of less than $9.42^{\circ}$. The actual figures bear out this estimation. Only 6 scattered femurs below $25 \mathrm{~mm}$ length have angles of obliquity less than the average adult and above that size only three have angles exceeding the adult average. Thus, obliquity has a developmental history akin to that of torsion, but in the opposite sense. Whereas torsion increases during the fetal period to exceed the adult value, obliquity decreases to less than the adult value.

\section{SUMMARY}

1. The material for this study was 53 femurs, mixed left and right, $8.4 \mathrm{~mm}$ to $110.6 \mathrm{~mm}$ in total shaft length, from 53 fetuses and neonatal infants $31 \mathrm{~mm}$ to $485 \mathrm{~mm}$ C-R length 
(9th fetal week to third postnatal week). Specimens were stripped to periosteum and cartilage, stained in alizarin in $\mathrm{KOH}$ and cleared in glycerin. Major dimensions were measured from projected line drawings taken from photographs of 4 views. In addition to linear dimensions, the angles of torsion, inclination, and obliquity were determined.

2. The regression of 10 femoral proportions (measurement/ total length of shaft) on length of ossified shaft is rectilinear with two exceptions : cartilage lengths, hyperbolic; diameter of the chondro-osseous junction, parabolic. Rectilinear equations also best express the regression of the angular dimensions on total length of shaft.

3. The femur is described as consisting of three growing units: the proximal and distal cartilages and the ossified shaft. Each cartilage is further divided, on the basis of growth processes, into intracapsular, extracapsular, and juxta-osseous parts.

4. The greatest change in proportion in the fetal period is in extent of ossification. The next greatest change is in the transverse dimensions across the proximal and distal cartilages. The least change is in diameters of the ossified shaft. This results in an increasing robustness of the ends of the femur in relation to its length. Comparison with postnatal femurs indicates that this trend is reversed sometime early in the postnatal period, for later femurs are more gracile.

5. The increasing robustness of the ends relative to the length of the femur may be attributed to the presence of large masses of cartilage at either end of the ossified shaft. These rapidly increase in diameter and advancing ossification replaces constantly larger diameters of cartilage. In the postnatal femur, with secondary centers present and ossification extending along the shaft to the level of the maximum diameters, relatively more cartilage is directly concerned with ossification than in the fetal femur.

6. The angular deviation of the proximal end of the shaft into trochanteric and neck planes begins in the latter third 
of the fetal period and increases rapidly. The distal end of the shaft is shown to become concave, at a period long before the onset of ossification of the secondary center. The position of the point of intersection of the axis of the medullary carity and the axis of the canal of the nutrient artery was examined in 10 selected femurs. It was found to be at approximately mid-shaft level in the smallest specimen and more proximal than distal in the largest. These changes in the ossified shaft are discussed in relation to shaft elongation and shape change.

7. Torsion is found to have a range in this series of from negative $26^{\circ}$ to positive $64^{\circ}$. The smallest femur had $7.5^{\circ}$ and the largest $52^{\circ}$ torsion. Torsion is estimated to increase by $0.49^{\circ}$ per $1 \mathrm{~mm}$ increase in femur length. With high individual variation, torsion generally exceeds the average adult value by the time the femur is $30 \mathrm{~mm}$ in length. A composite picture of torsion range in this and three other series is presented.

8. Inclination of the head-neck axis from the shaft increases slightly over the series. Obliquity of the shaft decreases in such a fashion that at term it is less than in the average adult femur.

\section{LITERATURE CITED}

AltMANA, F. 1924 Untersuchungen über die Torsio femoris und damit im Zusammenhang stehende Fragen. Z. Anat. Fntwg., 76: 82-126.

Aries, L. J. 1941 Experimental analysis of the growth pattern and rates of appositional and longitudinal growth in the rat femur. Surg., Gyn. Obst., 72: 679-689.

BardeEs, C. R. 1905 Studies of the development of the human skeleton. Am. J. Anat., 4 : 265-302.

BardeEs, C. R., AND W. H. Lewis 1901 The development of the limbs, body-wall, and back. Am. J. Anat., 1: 1-37.

BISGARD, J. D., AND M. E. BISGARD 1935 Longitudinal growth of long bones. Arch. Surg., 31: 568-578.

BRANDT, G. 1928 Die Torsion der unteren Extremität und ihre Bedeutung für die Deformitätenentstehung. Z. Orthop. Chir., 49: 481-541.

BRASH, J. C. 1934 Some problems in the growth and developmental mechanies of bone. Edin. Med. J., 41: 305-319, 363-386. 
Braus, H. 1904 Die Entwicklung der Form der Extremitäten und des Extremitätenskeletts. (In O. Hertwig's Handbuch der vergleichenden und experimentelien Entwickelungslehre der Wirbeltiere, 1: 16i-338) G. Fischer, Jena.

de Cuveland, E. F. 1950 Ein Beitrag zur Frage der Entstehung der Femurtorquierung im intrauterinen Leben. Z. Orthop. Chir., 44: 213-223.

DIGBY, K. N. 1916 The measurement of diaphysial growth in proximal and distal directions. J. Anat., 50: 187-188.

Doons, G. S. 1932 Osteoclasts and cartilage removal in endoehondral ossification in certain mammals. Am. J. Anat., 50:97-127.

Dodps, G. S., AND H. C. CAMERoN 1934 Studies on experimental rickets in rats. I. Structural modifications of the epiphyseal cartilages in the tibia and other bones. Am. J. Anat., $55: 135-155$.

ElFuMAN, H. 1945 Torsion of the lower extremity. Am. J. Phys. Anthrop., 39 (n.s. 3) : 146-163.

FRIEDLÄNDER, F. R. 1901 Ueber die Entstehung der angeborenen Hüftverrenhung. Z. Anat. Entwg., 9: 515-543.

GARDNER, E., AND D. J. GRAX 1950 Prenatal development of the human hip joint. Am. J. Anat., 87 : 163-211.

Gray, D. J., AND E. Gardner 1950 Prenatal changes in the human knee and superior tibiofibular joints. Am. J. Anat., 86: 235-288.

Grossberg 1924 Data cited by Ingalls, '24.

HAAS, S. L. 1917 The localization of the growing point in the epiphyseal cartilage plate of bones. Am. J. Orthop. Surg., 15: 563-586.

1931 Further observation on the transplantation of the epiphyseal cartilage plate. Surg., Gyu. Obst., 5\%: 958-963.

HAM, A. W. 1932 Cartilage and bone. (In Cowdry's Special Cytology, 2nd ed.) Hoeber, New York.

1953 Histology, 2nd ed, J. P. Lippineott Co., Philadelphia.

HARris, H. A. 1926 The growth of the long bones in childhood. Arch. Int. Med., 38: $785-806$.

1931 Lines of arrested growth in the long bones in childhood: the correlation of histological and radiographic appearances in clinical and experimental conditions. Brit. J. Radiol., 5 : 561-638.

Harris, H. A., AND A. E. Russeli 1933 The atypical growth of cartilage as the fundamental factor in dwarfism and achrondoplasia. Proc. Roy. Soc. Med., $26: 1-9$.

Hendryson, I. E. 1945 An evaluation of the estimated percentage of growth from the distal epiphyseal line. J. Bone Joint Surg., 2r: 208-210.

HRdička, A. 1920 Anthropometry. Wistar Institute, Philadelphia.

HumpHRY 1888 Observations on the angle of the neek of the thigh bone. J. Anat. Physiol., London, 23: 387-389.

INGALLs, N. W. 1924 Studies on the femur. General characteristies of the femur in the male white. Am. J. Phys. Anthrop., $7: 207-255$.

1927 Studies on the femur. IV. Some relations of the head and condyles in the white and negro. Am. J. Phys. Anthrop., 10: 393-405.

KEITH, A. 1919 Bone repair and growth. Brit. J. Surg., 5: 685-693. 
Kingsley, P. C., AND K. L. Olmstead 1948 A study of the angle of anteversion of the neck of the femur. J. Bone Joint Surg., 30: 745-751.

KRAHL, V. E. 1947 The torsion of the humerus: its localization, cause and duration in man. Am. J. Anat., 80: 275-319.

1948 The bicipital groove: a visible record of humeral torsion. Anat. Rec., 101: 319-331.

Krahl, V. E., ANd C. W. Mueller 1947 Permanent dry preparations of cartilage and bone. A method especially applicable to fetal material. Anat. Rec., $97: 41-45$.

Lacroix, P. 1949 L'organisation des os. Editions Desoer, Liege.

Le Damany, P. 1903a Les torsions osseuses. Leur role dans la transformation des membres. J. Anat. Physiol., Paris, 39: 126-134, 161-165.

1903b (Same title). J. Anat. Physiol., Paris, 39: 313-337. 1904 La cavite cotyloide. J. Anat. Physiol., Paris, 40: 387-413.

LïTKEN, P. 1950 Investigation into the position of the nutrient foramina and the direction of the vessel canals in the shafts of the humerus and femur in man. Acta Anat., 9:56-68.

MALL, F. P. 1918 On the age of human embryos. Am. J. Anat., 23: 397-422.

MARTIA, R. 1928 Lehrbuch der Anthropologie, 2nd ed., vol. I. G. Fiseher, Jena.

Maxinow, A. A., AND W. Bloom 1952 A Textbook of Histology, 6th ed. W. B. Saunders Co., Philadelphia.

MCLEAN, F. C., AND W. BLOOM 1940 Calcification and ossification. Caleification in normal growing bone. Anat. Rec., $78: 333-353$.

Mikulicz, A. 1879 Individuelle Formdifferenzen an Femur und Tibia des Menschen. Arch. Anat. Entwg., 36: 351-404.

Murray, P. D. F. 1936 Bones. A study of the development and structure of the vertebrate skeleton. Cambridge Univ. Press.

NobAck, C. R., AND E. NobACK 1944 Demonstrating the osseous skeleton of human embryos and fetuses. Stain Tech., 19: 51-54.

Patren, B. M. 1946 Human Embryology. The Blakiston Co., Philadelphia.

Payton, C. G. 1932 The growth in length of the long bones of the madder-fed pig. J. Anat., $66: 414-425$.

1934 The position of the nutrient foramen and the direction of the nutrient canal in the long bones of the madder-fed pig. J. Anat., 68: 500-511.

Pearson, K., AND J. BeLl 1919 A study of the long bones of the English skeleton. Part I. The femur. Draper's Co. Research Mem., Biometric Series $\mathrm{X}$, London.

PICK, J. W., J. K. Stack AND B. J. ANson 1944 Measurements on the human femur. I. Lengths, diameters and angles. Quart. Bull. Northwestern Cniv. Med. Seh., 15: 281-289.

Pitzen, P. 1923 Das mensehliche Femur während seiner Entwicklung. Arch. Anthrop., $19: 57-80$.

Rogers, S. P. 1931 A method of determining the angle of torsion of the neck of the femur. J. Bone Joint Surg., $13: 821-824$.

1934 Observations on torsion of the femur. J. Bone Joint Surg., $16: 281-289$. 
Strayer, L. M. 1943 The embryology of the human hip joint. Yale J. Biol. Med., $16: 13-26$.

StreEter, G. L. 1921 Weight, sitting height, head size, foot length, and menstrual age of human embryos. Carnegie Contrib. Embryol., 11: 143-170.

Weinmann, J. P., and H. Sicher 1947 Bone and Bones. Fundamentals of Bone Biology. C. V. Mosby Co., St. Louis. 